\title{
MONITORING PHENOLOGICAL VARIABILITY ACROSS A TROPICAL SAVANNA ARIDITY GRADIENT WITH REMOTE SENSING ACROSS SEASONAL TO ANNUALAND EXTREME EVENTS
}

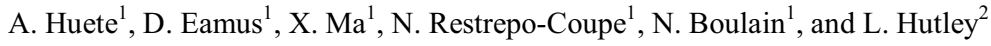 \\ ${ }^{1}$ Plant Functional Biology and Climate Change Cluster, University of Technology Sydney, NSW, Australia \\ (Alfredo.Huete@uts.edu.au) \\ ${ }^{2}$ Charles Darwin University, Darwin, NT, Australia (Lindsay.Hutley@cdu.edu.au)
}

Commission VIII, WG VIII/8

Keywords: Savannas, MODIS, VI, Tower fluxes

\begin{abstract}
:
Tropical savannas are key components of the global carbon and water cycles and understanding their functioning is critical to understanding ecosystem feedbacks to global climate. By observing broad scale vegetation responses to climatic variability, remote sensing offers powerful insights into the patterns and processes underlying savanna behaviour. However, savannas are highly complex, multi-layer and heterogenous ecosystems composed of $\mathrm{C} 3$ (herbaceous) and C4 (woodland) components with asynchronous phenological responses to environmental controls. There are concerns about optimizing the detection of savanna functioning as well as in understanding their environmental controls with remote-sensing data due to their coarse resolution. Furthermore, seasonalphenologic variations in satellite observations need to be sufficiently accurate to ensure confidence in interpreting vegetation responses to interannual climatic variation and to aid in constraining models of carbon and water fluxes. In this study, we analysed several years of high temporal frequency MODIS and TRMM satellite data sets of vegetation dynamics and rainfall, respectively, to seasonal and interannual responses of savanna multifunctional components to climate variability across a tropical savanna aridity gradient (1760 to $580 \mathrm{~mm}$ annual rainfall) in northern Australia. We compared our results with a series of eddy covariance (EC) tower flux data of gross primary production and analyzed a wide set of ecosystem processes including photosynthesis, net primary productivity, phenological metrics in timing of the growing season, and rain use efficiencies. We found MODIS satellite measurements to yield highly accurate spatial and temporal variability in ecosystem functioning and able to replicate interannual patterns and responses to rainfall observed with the EC tower data. Although these results appear promising for regional extensions of satelliteflux tower relationships at the landscape level, we also observed various issues with footprint matching and hysteresis effects that potentially may limit the utility of remote sensing in scaling fluxes of carbon and water to the regional scales.
\end{abstract}

